\title{
Mercury Speciation of Flue Gas Desulphurization By-Products in Coal-Fired Power Plants in China
}

\author{
Gang Tian, Hongyan Long, Yu Liu, Chen Zhang, Fan Zhang, Hongchang Wang, Jinwei Zhu, \\ Yanping Zhang, Hongmei Wang, Fan Wang*
}

Chinese Research Academy of Environmental Sciences, Beijing, China

Email: *fanwangsd@yahoo.com

How to cite this paper: Tian, G., Long, H.Y., Liu, Y., Zhang, C., Zhang, F., Wang, H.C., Zhu, J.W., Zhang, Y.P., Wang, H.M. and Wang, F. (2020) Mercury Speciation of Flue Gas Desulphurization By-Products in Coal-Fired Power Plants in China. Journal of Power and Energy Engineering, 8, 1-11. https://doi.org/10.4236/jpee.2020.811001

Received: September 23, 2020

Accepted: November 23, 2020

Published: November 26, 2020

Copyright $\odot 2020$ by author(s) and Scientific Research Publishing Inc. This work is licensed under the Creative Commons Attribution International License (CC BY 4.0).

http://creativecommons.org/licenses/by/4.0/

\begin{abstract}
The aim of this study was to develop and examine the morphology and distribution of mercury $(\mathrm{Hg})$ in flue gas desulfurization (FGD) by-product. Mercury in the coal of coal-fired power plants is concentrated in the by-products of desulfurization process, and it is widely used as an additive in cement, building materials and other industries. Due to the different stability of various forms of mercury in the environment, subsequent use of products containing desulfurization by-product additives will continue to be released into the environment, endangering human health. Therefore, it is very necessary to study the form and distribution of mercury in the by-products of desulfurization in coal-fired power plants to provide a theoretical basis for subsequent harmless treatment. For content and morphology of mercury analysis, 1 sample of dry FGD ash and 6 samples of wet FGD gypsum were analyzed. The total 7 samples were extracted using a modification of sequential chemical extractions (SCE) method, which was employed for the partitioning $\mathrm{Hg}$ into four fractions: water soluble, acid soluble, $\mathrm{H}_{2} \mathrm{O}_{2}$ soluble, and residual. The $\mathrm{Hg}$ analysis was done with United States Environmental Protection Agency (USEPA) method 7471B. Comparing with the wet FGD gypsums of coal-fired boilers, the total $\mathrm{Hg}$ content in the dry FGD by-product was as high as $1.22 \mathrm{mg} / \mathrm{kg}$, while the total $\mathrm{Hg}$ content in the FGD gypsum is $0.23-0.74$ $\mathrm{mg} / \mathrm{kg}$, which was 2 times over the wet FGD gypsum. The concentration of water soluble $\mathrm{Hg}$ in the dry FGD by-product was the highest amount $(0.72$ $\mathrm{mg} / \mathrm{kg}$ ), accounting for $59.02 \%$ of the total mercury. While residual $\mathrm{Hg}$ content was $0.16 \mathrm{mg} / \mathrm{kg}$, only about $13.11 \%$ of the total mercury. Mercury content in FGD gypsum was expressed in the form of $\rho$ (residual $\mathrm{Hg})>\rho\left(\mathrm{H}_{2} \mathrm{O}_{2}\right.$ soluble $\mathrm{Hg})>\rho$ (water soluble $\mathrm{Hg}$ ) $>\rho$ (acid soluble $\mathrm{Hg}$ ). The morphology and distribution of mercury in FGD by-products is supposed to be analyzed
\end{abstract}


before utilization, and the impact of mercury on the environment should be considered.

\section{Keywords}

Mercury, Mercury Speciation, Flue Gas, Desulphurization, By-Product, Sequential Chemical Extractions, Morphology and Distribution, Gypsum

\section{Introduction}

Mercury $(\mathrm{Hg})$ is highly toxic, highly volatile, and easy to be enriched in organisms to cause the disease of persistent environmental pollutants [1] [2] [3] [4]. Coal-fired power plants are the main cause of atmospheric mercury emissions in China, which ranks in the top two of the world's most substantial contributors [5]. Hg removal is achieved in the main through dust removal, flue gas desulfurization (FGD), and flue gas denitrification equipments [6]. FGD processes are mainly classified as dry desulfurization and wet desulfurization, and the by-products are FGD ash and FGD gypsum accordingly. Both can be used as cement additives, road construction material and for soil improvement [7]. The mercury in the process of resource utilization may be released into the environment, which will cause environmental pollution [8]. Evaluation of the mercury speciations and predicting its potential impact on the environment is critical in the disposal of FGD by-products.

Desulfurized fly ash includes fly ash, $\mathrm{CaSO}_{4}, \mathrm{CaSO}_{3}$ and unreacted desulfurizer [9]. Mercury exists in desulfurized fly ash in four states: 1) chloride, nitrate and sulfate existing in a water soluble state easily enters water body or soil during the stacking process and generates secondary pollution; 2) carbonate and $\mathrm{HgO}$, which cannot dissolve directly in water, but can dissolve in acidic conditions, causing secondary pollution to water or soil during acid rain or under other acidic conditions; 3 ) elemental mercury absorbed by fly ash or lime is not easily soluble in water, but will be released into the air during long-term stacking; and 4) inert mercury, lattice mercury, etc., mainly mercuric sulfide, are relatively stable in nature and are unlikely to be released or dissolve. They have the least impact on the environment.

Many studies have been carried on coal-fired FGD technology, yet there are fewer examinations of mercury's environmental stability in desulfurization by-products. Mercury in desulfurization by-products may be again released into the environment during stacking, dumping or comprehensive utilization and other disposal processes which are often used in dry process desulfurized fly ash. Secondary pollution is then caused. Therefore, studying the distribution of mercury speciation in desulfurized fly ash offers crucial guidance for assessing the migration and change of mercury in desulfurized fly ash in the natural gaseous and aqueous environment. It also facilitates an appraisal of the mercury pollu- 
tion effect that may be generated from the method of solid waste disposal and comprehensive utilization, and finally realize harmless treatment of desulfurized fly ash.

This study conducted experiments to extract mercury compounds from the seven solid samples, with the efforts to developed methods for specifying mercury in mercury-contaminated FGD residues.

\section{Methodology}

\subsection{FGD By-Products Samples}

Samples obtained of dry FGD by-products and wet FGD from 7 coal combustion power plants. The 6 FGD gypsum samples were collected from vacuum belts of the FGD system, and the other 1 sample of dry FGD ash samples was collected from the fabric filters.

\subsection{Sequential Chemical Extractions Method}

The total $\mathrm{Hg}$ was a poor indicator of the toxicological and environmental hazard associated with FGD residues, the sequential chemical extractions (SCE) [10] method was developed to separate mercury compounds of FGD by-products into 4 compound classes. Which were water soluble (mercuric chloride, mercuric nitrate and mercuric sulfate) $\mathrm{Hg}$, acid soluble (mercuric carbonate and mercuric oxide) $\mathrm{Hg}, \mathrm{H}_{2} \mathrm{O}_{2}$ soluble (elemental mercury and organic mercury) $\mathrm{Hg}$, and residual (with mercury sulfide and crystalloid based inert mercury) $\mathrm{Hg}$. And deionized water, $20 \mathrm{~mol} / \mathrm{L} \mathrm{HCl}, 30 \% \mathrm{H}_{2} \mathrm{O}_{2}$ solution, and nitrohydrochloric acid were employed as extractants, respectively.

The Hg determination of the SCE extracts was conducted with United States Environmental Protection Agency (USEPA) method 200.7.

The phase state analysis method of mercury in bottom mud and continuous chemical progressive method are referred to for samples of desulfurized gypsum to conduct pretreatment [11] [12], SCE is used to extract leaching solutions for different steps, and US EPA Method 200.7 is also adopted [13] [14], Please refer to Table 1 for the specific analytical steps.

\subsection{Analysis Methods and the Detection Limit}

Several spectral lines suitable for mercury determination are initially selected via instrument recommendation and with reference to a wavelength table. The spectral line with low background, limited interference and a high signal to noise ratio is taken as analytical spectral line $253.652 \mathrm{~nm}$ based on element interference. Hydride generation, inductive coupling and other ion emission spectrum (HG-ICP-AES) are used collectively to test blank solutions a total of 15 times in a way that is both separate and parallel. Mercury detection limit is calculated by using the results as follows:

$$
C_{L}=\frac{K S_{b}}{S}=\frac{3 S_{b}}{S}
$$


where, $S$-Sensitivity of the method;

$S_{b}$-Standard deviation of blank measurement;

$K$-The parameters were selected according to the requirement of confidence in the minimum value, rational value accepted 3.

The detection limit of element mercury is $0.14 \mathrm{ng} / \mathrm{ml}$. The method sets up the standard curve according to the content range of mercury in samples, and the linearly dependent coefficient of the standard curve of mercury $(r)$ is $\geq 0.999$.

\subsection{Accuracy Control Method}

The analytical performance of the HG-ICP-AES method established for verification concerning element mercury under different phase states ensures the accuracy of the measurement result. Computerized tests are conducted separately after diluting the standard solutions of mercury $(1000 \mu \mathrm{g} / \mathrm{ml})$. The outcome shows that the measurement result of the method falls within the range of standard value (refer to Table 2).

Table 1. The sequential chemical extractions procedure.

\begin{tabular}{|c|c|c|c|}
\hline Steps & & $\begin{array}{c}\text { Solid } \\
\text { Samples }\end{array}$ & $\begin{array}{l}\text { Liquid } \\
\text { Sample }\end{array}$ \\
\hline & $\begin{array}{c}\text { Take } 30 \mathrm{~g} \text { samples respectively, dry under } 105^{\circ} \mathrm{C} \text {, } \\
\text { and seal for analysis. }\end{array}$ & & \\
\hline A & $\begin{array}{l}\text { Extraction method of water-soluble mercury A. Take } 10 \mathrm{~g} \text { sample } \\
\text { of desulfurized fly ash and add it to } 200 \mathrm{ml} \text { deionized water, mix } \\
\text { and shock for } 30 \mathrm{~min} \text { under constant temperature, keep static } \\
\text { for } 2 \mathrm{~h} \text {, filtrate and separate residue and filter liquor. } \\
\text { The Ay of filter liquor is to be measured. }\end{array}$ & $\begin{array}{l}\text { Residue } \\
\text { drying }\end{array}$ & Ay \\
\hline B & $\begin{array}{l}\text { Extraction method of acid-soluble mercury B. To add residue of } \\
\text { A to } 150 \mathrm{ml} 20 \mathrm{~mol} / \mathrm{L} \mathrm{HCI}, \text { shake drastically, set down for } 5 \mathrm{~min} \\
\text { and add it to } 10 \mathrm{ml} 1 \% \text { of } \mathrm{CuSO}_{4} \text { solution, mix and shock for } 30 \mathrm{~min} \\
\text { under constant temperature, keep static for } 2 \mathrm{~h} \text {, filtrate and separate } \\
\text { residue and filter liquor. The By of filter liquor is to be measured. }\end{array}$ & $\begin{array}{l}\text { Residue } \\
\text { drying }\end{array}$ & By \\
\hline C & $\begin{array}{l}\text { Extraction method of hydrogen peroxide mercury C. To add } \\
\text { residue of } \mathrm{B} \text { to } 100 \mathrm{ml} 30 \% \text { of } \mathrm{H}_{2} \mathrm{O}_{2} \text {, add } 10 \mathrm{ml} \text { concentrated } \mathrm{HCI} \text {, } \\
\text { keep static for } 8 \mathrm{~h} \text {, filtrate and separate residue and filter liquor. } \\
\text { The Cy of filter liquor is to be measured. }\end{array}$ & $\begin{array}{l}\text { Residue } \\
\text { drying }\end{array}$ & Cy \\
\hline $\mathrm{D}$ & $\begin{array}{l}\text { Extraction method of lattice mercury } \mathrm{D} \text {. To add residue of } \mathrm{C} \text { to } \\
40 \mathrm{ml} \text { aqua regia, keep it digested for } 8 \mathrm{~h} \text {, filtrate and separate } \\
\text { residue and filter liquor. The Dy of filter liquor is to be measured. }\end{array}$ & & Dy \\
\hline
\end{tabular}

Table 2. Analysis of the HG-ICP-AES measurement.

\begin{tabular}{cccc}
\hline Element & $\begin{array}{c}\text { Standard value } \\
(\mu \mathrm{g} / \mathrm{ml})\end{array}$ & $\begin{array}{c}\text { Standard } \\
\text { uncertainty }\end{array}$ & $\begin{array}{c}\text { HG-ICP-AES } \\
(\mu \mathrm{g} / \mathrm{ml})\end{array}$ \\
\hline Mercury & 1.20 & 0.08 & 1.11 \\
\cline { 2 - 4 } & 2.31 & 0.21 & 2.07 \\
\hline
\end{tabular}




\section{Results and Discussion}

\subsection{Analysis of the FGD Processes and the By-Products}

Figure 1 is the dry FGD process diagram. Flue gas and desulfurizer are mixed in the thionizer by spraying in desulfurizer seriflux or desulfurizer and spray [15] [16], so as to realize FGD in the thionizer. Desulfurized by-products collected by bag filter still contain a certain amount of unreacted desulfurizer which enters the thionizer through circulation, ensuring the full reaction between $\mathrm{SO}_{2}$ in flue gas and desulfurizer. Adhered to the surface of the bag is desulfurizer which is not fully reacted. $\mathrm{SO}_{2}$ in flue gas continues to react with desulfurizer on the surface of the bag. This significantly prolongs the reaction duration and improves the utilization factor and desulfurization efficiency of desulfurizer.

Figure 2 shows the typical limestone-gypsum wet FGD process. To achieve higher desulfurization efficiency, wet FGD is used by taking limestone as desulfurizer. Flue gas enters the double circulation absorption tower and is purified after reacting with limestone via two series-wound circulation and washing process. The two circulations of flue gas washing area are Quench circulation (first-level circulation) and Absorber circulation (second-level circulation). Flue gas enters the second-level circulation and washing area and is washed again by high $\mathrm{pH}$ seriflux after it is washed by low $\mathrm{pH}$ seriflux in the first-level washing area, so that the emission concentration of $\mathrm{SO}_{2}$ in flue gas is lower than $35 \mathrm{mg} / \mathrm{m}^{3}$. Spray serifluxes of different $\mathrm{pH}$ values are stored in the stock chest of the absorption tower and Absorber Feed Tank (AFT), respectively. The seriflux in the stock chest of the absorption tower is low $\mathrm{pH}$ value, and that of AFT is high $\mathrm{pH}$ value.

\subsection{Total Mercury Contents Analysis for FGD By-Products}

Figure 3 is the contents of total Hg in the dry FGD by-products and wet FGD gypsum. Compared with the fly ash, the contents of total Hg in the dry FGD ash is $1.22 \mathrm{mg} / \mathrm{kg}$, while the content of total $\mathrm{Hg}$ in the wet FGD gypsum is $0.23-0.74$ $\mathrm{mg} / \mathrm{kg}$, which is about 3 times of the content of total $\mathrm{Hg}$ in the FGD gypsum.

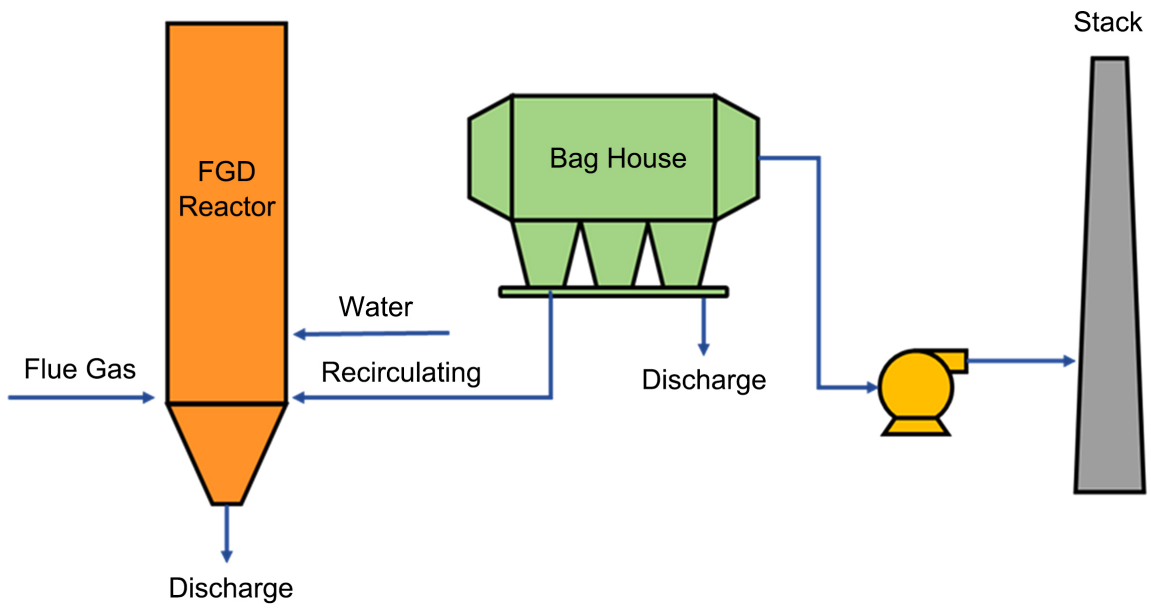

Figure 1. Dry FGD process diagram. 


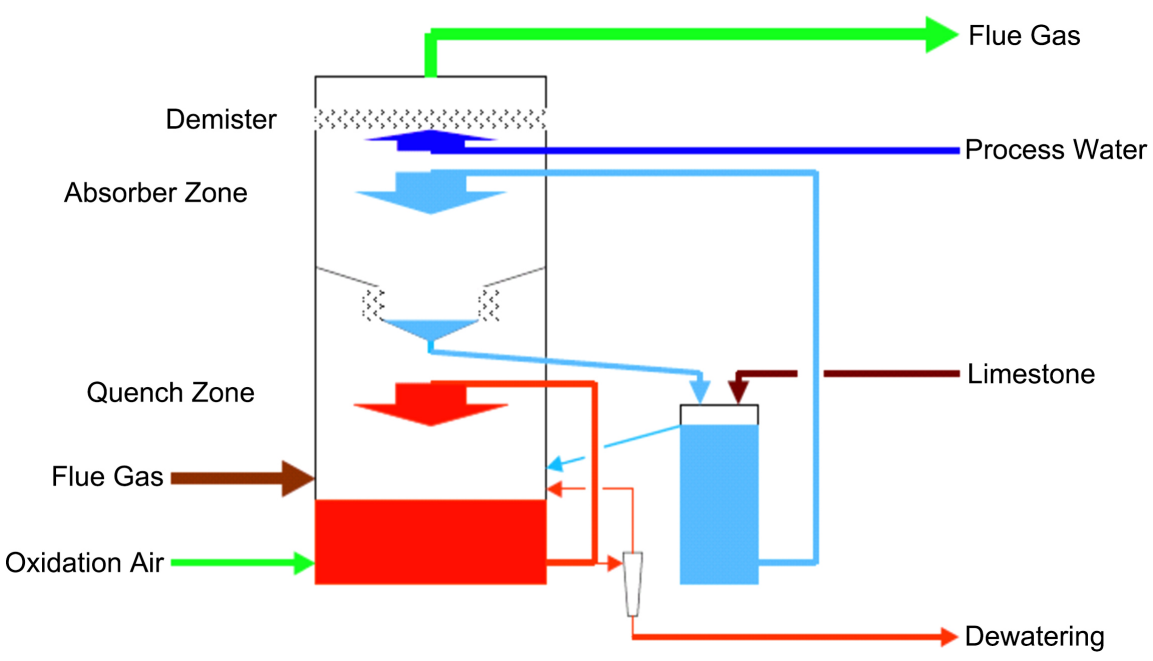

Figure 2. Wet FGD process diagram.

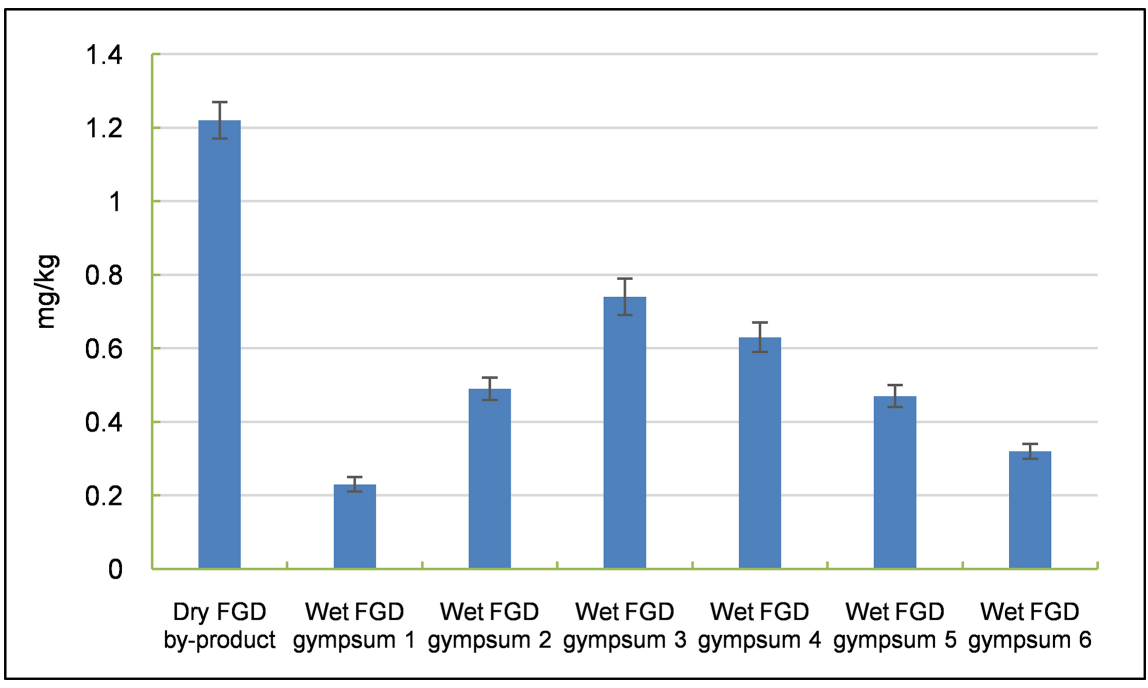

Figure 3. The contents of total Hg in the dry FGD by-products and wet FGD gypsum.

Due to the low temperature of flue gas in the bag filter, the desulfurization ash adheres to the surface of the bag, which prolongs the contact adsorption time of fly ash and lime desulfurizer with mercury vapor, which is conducive to the physical and chemical adsorption of mercury vapor by desulfurization ash, as more Hg can be adsorbed by the dust collector than that of the wet FGD process.

Figure 4 and Figure 5 are the Scanning Electron Microscope (SEM) images of dry and wet FGD by-products. After comparison, it's found that dry FGD by-product has more micropores on the surface, which is conducive to improving the mercury absorption action. Circulated desulfurized fly ash and desulfurizer have larger specific surface area and stronger absorption capacity of mercury vapor. Meanwhile, desulfurized fly ash particles bind to the surface of the bag, extending the absorption time of desulfurizer of mercury vapor. Mercury vapor changes to granular mercury collected by the bag filter, which helps collect most of the granular mercury [17]. 


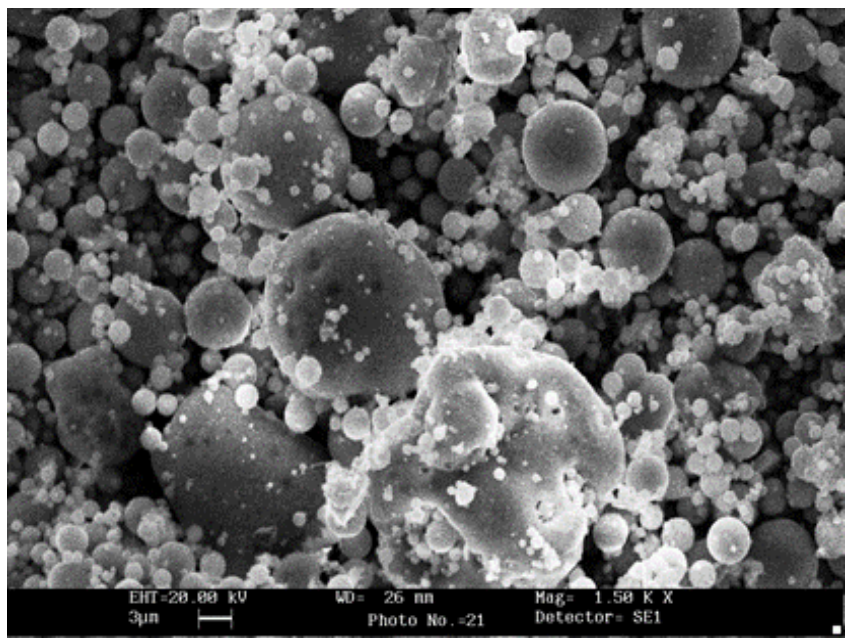

Figure 4. SEM image of dry FGD by-product.

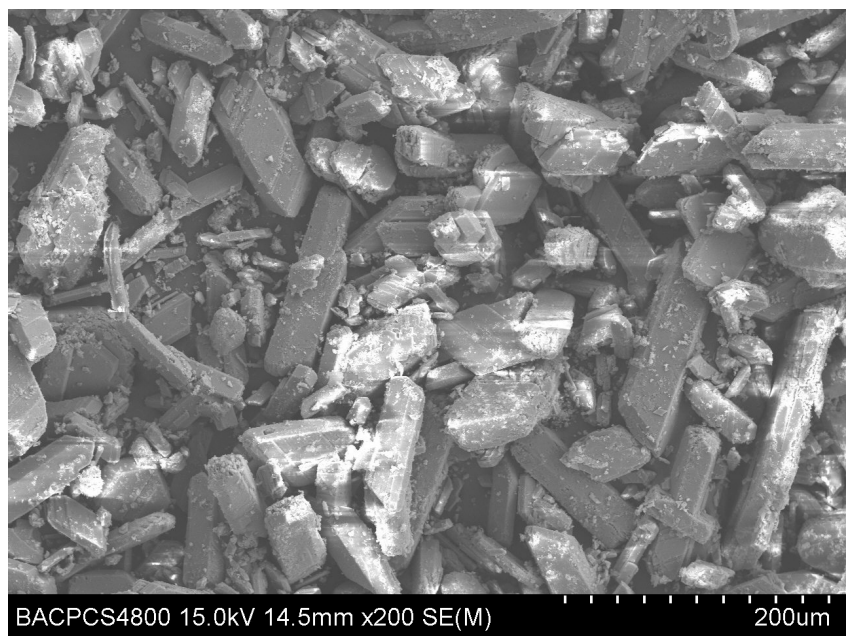

Figure 5. SEM image of wet FGD gypsum.

\subsection{The Mercury Speciation Content in FGD By-Products}

Table 3 and Table 4 show the distribution and percentage contents of different forms of mercury in the FGD by-products, respectively.

The concentration of water soluble $\mathrm{Hg}$ in the dry FGD by-product was the highest amount of $0.72 \mathrm{mg} / \mathrm{kg}$, accounting for $59.02 \%$ of the total mercury. while residual $\mathrm{Hg}$ content was $0.16 \mathrm{mg} / \mathrm{kg}$, only about $13.11 \%$ of the total mercury.

The contents of water-soluble mercury and $\mathrm{H}_{2} \mathrm{O}_{2}$ mercury in dry FGD by-products are clearly higher than other samples. This is in the main determined by the element of mercury vapor in flue gas. Mercury vapor in flue gas primarily exists in the forms of $\mathrm{Hg}_{\mathrm{g}}^{0}$ and $\mathrm{Hg}_{\mathrm{g}}^{2+}$, including around $20 \%-50 \%$ of $\mathrm{Hg}_{\mathrm{g}}^{0}$ and $50 \%-80 \%$ of $\mathrm{Hg}_{\mathrm{g}}^{2+}$ [18]. As the temperature of flue gas in the bag filter is low, desulfurized fly ash adheres to the surface of bag, extending the contact and absorption time of fly ash and lime desulfurizer with mercury vapor. This aids the physical and chemical absorption of desulfurized fly ash of mercury vapor and enables the bag filter to absorb more $\mathrm{Hg}_{\mathrm{g}}^{0}$ and $\mathrm{Hg}_{\mathrm{g}}^{2+}$. 
Table 3. Mercury speciation of the FGD by-product samples.

\begin{tabular}{cccccc}
\hline Samples & $\begin{array}{c}\text { Water soluble } \\
\mathrm{Hg}(\mathrm{mg} / \mathrm{kg})\end{array}$ & $\begin{array}{c}\text { Acid soluble } \\
\mathrm{Hg}(\mathrm{mg} / \mathrm{kg})\end{array}$ & $\begin{array}{c}\mathrm{H}_{2} \mathrm{O}_{2} \text { soluble } \\
\mathrm{Hg}(\mathrm{mg} / \mathrm{kg})\end{array}$ & $\begin{array}{c}\text { Residual Hg } \\
(\mathrm{mg} / \mathrm{kg})\end{array}$ & $\begin{array}{c}\text { Total Hg } \\
(\mathrm{mg} / \mathrm{kg})\end{array}$ \\
\hline Dry FGD by-product & 0.72 & 0.14 & 0.20 & 0.16 & 1.22 \\
Wet FGD gypsum 1 & 0.03 & 0.01 & 0.08 & 0.11 & 0.23 \\
Wet FGD gypsum 1 & 0.09 & 0.06 & 0.21 & 0.16 & 0.52 \\
Wet FGD gypsum 2 & 0.15 & 0.10 & 0.22 & 0.27 & 0.74 \\
Wet FGD gypsum 3 & 0.17 & 0.12 & 0.19 & 0.20 & 0.68 \\
Wet FGD gypsum 4 & 0.09 & 0.06 & 0.18 & 0.16 & 0.49 \\
Wet FGD gypsum 5 & 0.04 & 0.02 & 0.08 & 0.12 & 0.26 \\
\hline
\end{tabular}

Table 4. Percentage of the mercury speciation.

\begin{tabular}{ccccc}
\hline Samples & $\begin{array}{c}\text { Water soluble } \mathrm{Hg} \\
(\%)\end{array}$ & $\begin{array}{c}\text { Acid soluble } \mathrm{Hg} \\
(\%)\end{array}$ & $\begin{array}{c}\mathrm{H}_{2} \mathrm{O}_{2} \text { soluble } \mathrm{Hg} \\
(\%)\end{array}$ & $\begin{array}{c}\text { Residual Hg } \\
(\%)\end{array}$ \\
\hline Dry FGD by-product & 59.02 & 11.48 & 16.39 & 13.11 \\
Wet FGD gypsum 1 & 13.04 & 4.35 & 34.78 & 47.83 \\
Wet FGD gypsum 1 & 17.31 & 11.54 & 40.38 & 30.77 \\
Wet FGD gypsum 2 & 20.27 & 13.51 & 29.73 & 36.49 \\
Wet FGD gypsum 3 & 25.00 & 17.65 & 27.94 & 29.41 \\
Wet FGD gypsum 4 & 18.37 & 12.24 & 36.73 & 32.65 \\
Wet FGD gypsum 5 & 15.38 & 7.69 & 30.77 & 46.15 \\
\hline
\end{tabular}

The Hg content in the wet FGD gypsum is expressed in the form of water soluble $\mathrm{Hg}(0.03-0.17 \mathrm{mg} / \mathrm{kg})$, acid soluble $\mathrm{Hg}(0.01-0.12 \mathrm{mg} / \mathrm{kg})$, hydrogen peroxide soluble $\mathrm{Hg}(0.08-0.22 \mathrm{mg} / \mathrm{kg})$, and the residual $\mathrm{Hg}(0.11-0.27 \mathrm{mg} / \mathrm{kg})$, which cover the percentages of $13.04 \%-25.00 \%, 4.35 \%-17.65 \%, 27.94 \%-$ $40.38 \%$, and $29.41 \%-47.83 \%$, respectively. Mercury content in wet FGD gypsum was expressed in the form of $\rho$ (residual $\mathrm{Hg})>\rho\left(\mathrm{H}_{2} \mathrm{O}_{2}\right.$ soluble $\left.\mathrm{Hg}\right)>\rho$ (water soluble $\mathrm{Hg})>\rho$ (acid soluble $\mathrm{Hg}$ ).

Mercury in wet desulfurization gypsum mostly exists in the forms of $\mathrm{H}_{2} \mathrm{O}_{2}$ soluble and Residual, accounting for $70.61 \%$ of total mercury on average. Compared with dry FGD by-products, mercury in the two forms only accounts for $29.50 \%$ of total mercury. This is mainly because spraying desulfurized seriflux in the wet desulfurization process can absorb divalent mercury compounds in flue gas. Relatively smaller amounts of water-soluble mercury and acid-soluble mercury enter desulfurized gypsum through crystallization as the content of mercury compounds in flue gas is also relatively lower.

In the meantime, the fly ash in flue gas enters desulfurized seriflux and 
enriches through repeated desulfurized seriflux circulation under wet FGD process [19], as shown in Figure 4. Fly ash mercury may be attached to the surface of microsphere or micelle in the form of zero-valent simple substance, and some mercury may replace other metallic elements with divalent combined state and combine in lattice, such as HgS. Therefore, most mercury is mainly contained in particles in wet desulfurized gypsum and, at the same time, particles have more lattice mercury.

\section{Conclusions}

The stability and potential impact on environment of $\mathrm{Hg}$ should be taken into account regarding the utilization of the solid by-products from the coal-fired power plants, especially for the FGD by-products.

It was assumed that the wet FGD gypsum was safer in utilization, since the total $\mathrm{Hg}$ concentration was about $0.23-0.74 \mathrm{mg} / \mathrm{kg}$, composing mainly the inert mercury, including the $\mathrm{H}_{2} \mathrm{O}_{2}$ soluble mercury and the residual mercury. While the total $\mathrm{Hg}$ concentration of dry FGD by-product was much higher than that of wet FGD gypsum, which is as high as $1.22 \mathrm{mg} / \mathrm{kg}$.

Because the retention time of dry FGD is much longer in FGD reactor and the baghouse, the content of water soluble $\mathrm{Hg}$ is over $0.72 \mathrm{mg} / \mathrm{kg}$, which is mainly accumulated with mercuric chloride, mercuric nitrate and mercuric sulfate from the flue gas, covering the percentage of $59.02 \%$ correspondently. The dry FGD residual is mainly composed of large particles of FGD agent settled down by the FGD equipment or the fabric filters, and the residual $\mathrm{Hg}$ concentration is 0.16 $\mathrm{mg} / \mathrm{kg}$, which accounts only $13.11 \%$ of the total mercury.

The Hg content in the FGD gypsum is expressed in the form of water soluble $\mathrm{Hg}(0.03-0.17 \mathrm{mg} / \mathrm{kg})>$ acid soluble $\mathrm{Hg}(0.01-0.12 \mathrm{mg} / \mathrm{kg})>$ hydrogen peroxide soluble $\mathrm{Hg}(0.08-0.22 \mathrm{mg} / \mathrm{kg})>$ residual $\mathrm{Hg}(0.11-0.27 \mathrm{mg} / \mathrm{kg})$, which cover the percentages of $13.04 \%-25.00 \%, 4.35 \%-17.65 \%, 27.94 \%-40.38 \%$, and $29.41 \%-47.83 \%$, respectively.

In wet desulfurization gypsums, mercury mostly exists in the states of $\mathrm{H}_{2} \mathrm{O}_{2}$ soluble and Residual, accounting for $70.61 \%$ of total mercury on average. Compared to dry FGD by-products, mercury in the two forms only accounts for $29.50 \%$ of total mercury.

This study proposes a detection method for the form and distribution of mercury in the desulfurization by-products of coal-fired power plants, which provides strong support for the subsequent research on the harmlessness of desulfurization by-products.

\section{Acknowledgements}

This study was supported by the National Key Research and Development Program of China (No. 2016YFC0204100 \& 2019YFC0214201), key research and development program of Shandong Province (No. 2018CXGC1015), and by State Key Laboratory of Solid Waste Reuse for Building Materials (No. SWR2019001). 


\section{Conflicts of Interest}

The authors declare no conflicts of interest regarding the publication of this paper.

\section{References}

[1] Zhang, J.Y., Ren, D., Xu, D., et al. (1999) The Distribution of Mercury in Major Associated Minerals from Coal Beds in Southwestern Guizhou. Geological Review, 45, 539-542.

[2] Carpi, A. (1997) Mercury from Combustion Sources: A Review of the Chemical Species Emitted and Their Transport in the Atmosphere. Water, Air and Soil Pollution, 98, 241-254. https://doi.org/10.1007/BF02047037

[3] William, L.B., Karl, S. and Kandance, K. (2007) Testing Mechanisms of Mercury Retention in FGD Products. The 2007 World of Coal Ash Conference, Vol. 5, 7-10.

[4] Izquierdo, M.T., De Las Obras-Loscertales, M., De Diego, L.F., et al. (2017) Mercury Emissions from Coal Combustion in Fluidized Beds under Oxy-Fuel and Air Conditions: Influence of Coal Characteristics and $\mathrm{O}_{2}$ Concentration. Fuel Processing Technology, 167, 695-701. https://doi.org/10.1016/j.fuproc.2017.08.021

[5] Chu, P. and Porcella, D.B. (1995) Mercury Stack Emissions from U.S. Electric Utility Plants. Water Air Soil Pollution, 80, 135-144. https://doi.org/10.1007/978-94-011-0153-0_16

[6] Yang, Y.F., Huang, Q.F. and Wang, Q. (2012) Ignoring Emissions of Hg from Coal Ash and Desulfurized Gypsum Will Lead to Ineffective Mercury Control in Coal-Fired Power Plants in China. Environmental Science \& Technology, 46, 3058-3059. https://doi.org/10.1021/es300786d

[7] Cheng, C.M., Chang, Y.N., Sistani, K., et al. (2009) Emission and Leaching Potential of Mercury from Flue Gas Desulfurization (FGD) By-Products Amended Soil. World of Coal Ash Conference, Lexington, Vol. 5, 4-7.

[8] Senior, C.L., Helble, J.J. and Sarofim, A.F. (2000) Emissions of Mercury, Trace Elements, and Fine Particles from Stationary Combustion Sources. Fuel Processing Technology, 65-66, 263-288. https://doi.org/10.1016/S0378-3820(00)00082-5

[9] Wang, H., Duan, Y., Li, Y.N., et al. (2016) Experimental Study on Mercury Oxidation in a Fluidized Bed under $\mathrm{O}_{2} / \mathrm{CO}_{2}$ and $\mathrm{O}_{2} / \mathrm{N}_{2}$ Atmospheres. Energy \& Fuels, 30, 5065-5070. https://doi.org/10.1021/acs.energyfuels.6b00457

[10] Tessier, A., Campbell, P.G.C. and Bisson, M. (1979) Sequential Exaction Procedure for the Speciation of Particulate Trace Metals. Analytical Chemistry, 51, 844-851. https://doi.org/10.1021/ac50043a017

[11] David, O.C., Hou, D.Y., Yong, S.O., et al. (2017) Mercury Speciation, Transformation, and Transportation in Soils, Atmospheric Flux, and Implications for Risk Management: A Critical Review. Environment International, 126, 747-761. https://doi.org/10.1016/j.envint.2019.03.019

[12] Neculita, C.M., Zagury, G.J. and Deschênes, L. (2005) Mercury Speciation in Highly Contaminated Soils from Chlor-Alkali Plants Using Chemical Extractions. Journal of Environmental Quality, 34, 255-262.

[13] Park, C.H.E., Lee, Y., Lee, L.J.-E., et al. (2013) Simple and Accessible Analytical Methods for the Determination of Mercury in Soil and Coal Samples. Chemosphere, 93, 9-13. https://doi.org/10.1016/j.chemosphere.2013.04.044

[14] USEPA Method 200.7, Determination Trace Elements Inductively Coupled Plas- 
ma-Atomic Emission Spectrometry. Revision 4.4, EMMC Version.

[15] Ma, X.X., Kaneko, T., Tsutomu, T., et al. (2000) Use of Lime for $\mathrm{SO}_{2}$ Removal from Flue Gas in the Semidry FGD Process with a Powder-Particle Spouted Bed. Chemical Engineering Science, 55, 4643-4652.

https://doi.org/10.1016/S0009-2509(00)00090-7

[16] Sanders, J.F., Keener, T.C. and Wang, J. (1995) Heated Fly Ash/Hydrated Lime Slurries for $\mathrm{SO}_{2}$ Removal in Spray Dryer Absorbers. Industrial \& Engineering Chemistry Research, 34, 302-307. https://doi.org/10.1021/ie00040a032

[17] Joseph, R.V.F., Richard, A.H., William, J.O.D., et al. (2003) Modeling Sorbent Injection for Mercury Control in Baghouse Filters: II-Pilot-Scale Studies and Model Evaluation. Journal of the Air \& Waste Management Association, 53, 489-496. https://doi.org/10.1080/10473289.2003.10466172

[18] Zhao, Y.C., Zhang, J.Y., Liu, J., et al. (2010) Study on Mechanism of Mercury Oxidation by Fly Ash from Coal Combustion. Engineering Thermophysics, 55, 163-167. https://doi.org/10.1007/s11434-009-0567-7

[19] Bhardwaj, R., Chen, X. and Vidic, R.D. (2012) Impact of Fly Ash Composition on Mercury Speciation in Simulated Flue Gas. Journal of the Air \& Waste Management Association, 59, 1331-1338. https://doi.org/10.3155/1047-3289.59.11.1331 